\title{
THE ACTION OF SUNLIGHT AND AIR UPON SOME LUBRICATING OILS
}

\author{
By C. E. Waters
}

In 1885 Schaal $^{1}$ patented a process for the manufacture of soaps by the action of air upon mineral oils in the presence of alkaline substances. This was based on an older observation of Engler's.

In I89 I Zaloziecki ${ }^{2}$ studied the oxidation of petroleum by means of air. By blowing cold air through the oil the oxidation was slight, but was greatly increased in the presence of sodium hydroxide. The acidity shown by methyl orange, as opposed to phenolphthalein, he believed to be due to the oxidation of mercaptans and organic sulphides, and not to the presence of traces of the acid used in refining.

Schestopal ${ }^{3}$ found that illuminating oils absorbed several volumes of oxygen at room temperature when inclosed in sealed tubes laid horizontally. He pointed out the bearing this had upon the treatment of kerosene in agitators.

Holde ${ }^{4}$ exposed mineral and vegetable oils to the air for a long time, studying changes in the viscosity, specific gravity, etc. He found that the changes were much less for mineral than for vegetable oils.

Haack ${ }^{5}$ believed that the oxidation observed in refining oils was due to the combined action of sulphuric acid and air. This

\footnotetext{
${ }^{1}$ D. R. P. 32705 ; Chem.-Ztg., 9, p. I520; 1885.

${ }^{2} Z$. angew. Chem., 1891, pp. 4I6-Ig.

${ }^{3}$ Chem.-Ztg., 15 , pp. $35^{2-4}$; I8gr.

${ }^{4}$ Mitth. kgl. techn. Versuchsanst., 10, pp. 85-90; 1892; J. Soc. Chem. Ind., 11, p. $619 ; 1892$.

${ }^{5}$ Chem.-Ztg., 16, p. 694; I892. 
idea was upheld by Kern. ${ }^{6}$ Other papers bearing upon the question of oxidation by atmospheric oxygen were published.?

Zaloziecki ${ }^{8}$ studied the influence of light and air upon the acid treatment of kerosene. In some of his experiments he used colored glass. The general conclusion reached by him was that light and air should be excluded. Ostrejko, ${ }^{9}$ confirmed this work as to the effect on the color of refined petroleum, and also determined the increase in acidity due to oxidation. Wischin ${ }^{10}$ thought that the darkening in color of kerosene was perhaps due to a molecular rearrangement of dissolved asphalt under the influence of actinic rays.

Hirsch ${ }^{11}$ passed air through mineral oils in the presence of soda lye, and even after i 2 hours at $70^{\circ}$ could detect no change in the alkali, concluding from this that there was no oxidation. Aisinmann ${ }^{12}$ found that the absorption of oxygen was very slight. It was also stated by Künkler and Schwedholm ${ }^{13}$ that there was no increase in weight when mixtures of mineral oil with bone oil, olive oil, etc., were rubbed up with sand or pumice and exposed to the air. The resinification noticed was believed to be due solely to polymerization.

There can be no doubt, however, that oxidation really takes place. Charitschkow, ${ }^{14}$ who states that the resinous products formed in petroleum on long standing under the combined influence of light, air, and moisture are nearly identical with those of Schaal, obtained sirup-like acids ${ }^{15}$ by the action of air in the presence of alkalies. These acids, which are nearly insoluble in benzine and petroleum ether, he calls "polynaphthene," or "asphaltogenic" acids, the latter name being self-explanatory.

${ }^{6}$ Chem.-Ztg., 17, p. 706; I893.

${ }^{7}$ Zaloziecki: Chem.-Ztg., 16, p. 591; r892. Holde: Ibid., 18, 704, pp. I737, I935; I894. Hirsch: Ibid., 18, p. I824.

${ }^{8}$ Ibid., 19, 875-7, 956-8; p. 1895 .

${ }^{9}$ See J. Soc. Chem. Ind., 15, p. 345 ; 1896.

${ }^{10}$ Chem. Rev. Fett-Harz-Ind., 1895, Nos. 26 and 27; J. Soc. Chem. Ind., 14, p. Io39; 1895 .

${ }^{11}$ Chem.-Ztg., 19, p. 4I; I895.

${ }_{12}$ Dingl. pol. J., 294, p. 658; I894; J. Soc. Chem. Ind., 14, p. 282; 1895.

${ }^{13}$ Seifensiederztg., 35, p. 34I; Chem. Zentr., 1908, II; 1859.

${ }^{14} \mathrm{Z}$. angew. Chem., 21, p. II 55 ; 1908 .

${ }^{15}$ Chem.-Ztg., 33, p. I165; Ig09. 
Meyerheim ${ }^{16}$ in this connection, thinks the increase in asphalt content with lapse of time is due to polymerization or to a change from the original colloidal condition to the insoluble form. His experiments were carried out in closed bottles two-thirds filled with oil. The changes in asphalt content in two oils, kept in the dark, in diffused light, and under the influence of radium emanations, were determined. After 8 months no difference due to the action of radium could be detected. In diffused light one oil showed a higher asphalt content than a control kept in the dark; the other oil showed the same content of asphalt as the control.

Molinari and Fenaroli ${ }^{17}$ obtained unstable ozonides from petroleum hydrocarbons. They were precipitated from their solutions in benzine, ether, or chloroform by means of petroleum ether. They decomposed at $20^{\circ}$ and changed at $35^{\circ}-50^{\circ}$ into a soft, red substance which was converted into a resinous mass at $105^{\circ}$.

An interesting observation bearing on the work described in this paper was made by Ackermann. ${ }^{18}$ A sample of naphtha from Russian Turkestan was entirely thickened on exposure to the sun's heat for a whole year in an open vessel. Fresh samples of naphtha yielded 76.68 per cent of distillate between $20^{\circ}$ and $310^{\circ}$, while the thickened oil yielded only 15.67 per cent of distillate.

In a paper entitled "Studies on the Carbenes" Mackenzie ${ }^{19}$ shows that the action of light upon solutions of asphalt in carbon tetrachloride greatly increases the percentage of "carbenes" or insoluble bitumens. This is shown to be due to the formation of hydrochloric acid, which precipitates the carbenes.

The present writer was at the time determining asphaltic material in certain lubricating oils, and the above-mentioned paper, though on a somewhat remotely related subject, suggested the experiments herein described.

Three samples of oil were used. $\mathrm{B}$ and $\mathrm{C}$ were straight mineral oils; B was moderately dark in color, while C was much lighter

\footnotetext{
${ }^{16}$ Ibid., 34, p. 454; Igro.

17 Ber. d. chem. Ges., 41, p. 3704; 1908.

${ }^{18}$ Chem.-Ztg., 34, p. 440; I9ro.

${ }_{19} \mathrm{~J}$. Ind. Eng. Chem., 2, pp. I24-127; I9ro.
} 
colored and less viscous. D resembled $\mathrm{B}$ in color and viscosity, but contained approximately 0.5 per cent of fatty oil.

Duplicate samples of $20 \mathrm{~g}$ each were weighed into $\mathrm{I} 5 \mathrm{O} \mathrm{cc}$ Erlenmeyer flasks, loosely covered with caps to exclude dust and rain, and were exposed outside a window facing south for 23 days. Within 2 or 3 days the samples began to have a slight cloudiness, and after a week or ıo days the insoluble matter formed a cake on the bottom. After 23 days the contents of each flask were diluted with $50 \mathrm{cc}$ of ligroin and after 36 hours the insoluble matter was filtered off in Gooch crucibles, washed with ligroin, dried at $100^{\circ}$ and weighed. The following percentages of insoluble matter were found:

\begin{tabular}{c|c|c|c|c|c|c}
\hline Sample & B & B & C & C & D & D \\
\cline { 2 - 6 } Insoluble (per cent)......... & 0.77 & 1.03 & 2.42 & 2.86 & 1.40 & 1.91 \\
\hline
\end{tabular}

The discrepancies between duplicate samples are believed to be due to their having received unequal amounts of sunlight, as it was necessary to place the flasks in a crystallizing dish to prevent their blowing away, and late in the afternoon those outside were in the sun longer than the others.

Another test was then started with approximately ro-g samples, the flasks being weighed at intervals. After each weighing the flasks which showed the least gain were placed so as to receive the maximum of sunlight. For this reason the last figures given in the next table are more concordant than they would otherwise have been.

\begin{tabular}{|c|c|c|c|c|c|c|}
\hline Sample & B & B & C & C & D & $\mathrm{D}$ \\
\hline Weight of oil.. & 10.002 & 10.012 & 10.025 & 10.023 & 10.023 & 10.003 \\
\hline \multicolumn{7}{|l|}{ Total gain after- } \\
\hline 31 days (g). & 0.176 & 0.152 & 0.187 & 0.183 & 0.154 & 0.139 \\
\hline 46 days $(\mathrm{g})$. & 0.192 & 0.174 & 0.215 & 0.207 & 0.176 & 0.159 \\
\hline 80 days $(\mathrm{g})$ & 0.233 & 0.223 & 0.274 & 0.278 & 0.221 & 0.201 \\
\hline 110 days $(\mathrm{g})$. & 0.277 & 0.263 & 0.327 & 0.340 & 0.274 & 0.243 \\
\hline 132 days $(\mathrm{g})$. & 0.290 & 0.289 & 0.358 & 0.369 & 0.297 & 0.268 \\
\hline
\end{tabular}


That the increase in weight is somewhat influenced by the temperature, and is not entirely due to rays of short wave length, seems clear from the results obtained when two lots of oil B were exposed in very shallow dishes made by cutting off the bottoms of two beakers of the same diameter. One was covered with a thick watch glass. The other was uncovered, and was so shallow that hardly any light passed through glass before falling on the oil. The results follow:

\begin{tabular}{|c|c|c|}
\hline Dish & Uncovered & Covered \\
\hline Weight of oil........... & 10.001 & 10.001 \\
\hline Gain after 6 hours bright, sun $(\mathrm{g}) \ldots \ldots$ & 0.0354 & 0.0354 \\
\hline Further gain after 6 hours, bright sun. . & 0.0183 & 0.0198 \\
\hline Further gain after $\sigma$ hours, bright sun.......... & 0.0154 & 0.0179 \\
\hline Further gain after 6 hours, partly cloudy. & 0.0085 & 0.0094 \\
\hline Further gain after 4 hours, partly cloudy......... & 0.0050 & 0.0061 \\
\hline Further gain after 6 hours, dull one-half of time.. & 0.0059 & 0.0068 \\
\hline Further gain after 6 hours, dull one-third of time. & 0.0063 & 0.0071 \\
\hline Further gain after 6 hours, dull one-half of time.. & 0.0049 & 0.0065 \\
\hline Total gain $(\mathrm{g}) .$. & 0.0997 & 0.1090 \\
\hline
\end{tabular}

In the cool, windy weather then prevailing, the oil in the covered dish must have been warmer than that in the uncovered one. On the first five days the dishes rested on white paper. This was replaced by black paper on the last three days, but only a slight change in the results was noticed. The increasing opacity of the oil owing to the formation of insoluble matter and the increasing saturation with oxygen would both tend to mask any effect due to a slight rise in temperature. Traces of precipitate were noticed at the end of the first six hours.

The above results show only that the temperature exerts some influence, but do not enable one to decide whether or not the part played by light is of greater or less importance. We then heated IO.OI $4 \mathrm{~g}$ of the oil in a flask with ground-in stopper, connected with an air-purifying train and a calcium chloride tube, followed by a flask containing baryta water. The flask was then placed in a water bath made of a porcelain beaker surrounded by 
a sheet-iron cylinder. The top was covered with a perforated metal plate. The projecting neck of the flask was wrapped in cloth to exclude light. Under these conditions the oil was heated in a very slow current of dry air to $40^{\circ}$, for 16 hours in all, on three consecutive days. So little barium carbonate was precipitated that the heating was continued for six and a half hours on each of two consecutive working days, to $50^{\circ}, 60^{\circ}, 70^{\circ}, 80^{\circ}$, and $90^{\circ}$. Even then it was not thought worth while to determine the small amount of carbon dioxide precipitated as barium carbonate. The calcium chloride tube showed a gain of o.or 56 $\mathrm{g}$, while the flask, instead of gaining in weight, lost $0.0030 \mathrm{~g}$.

More of the same oil, II.274 g, was exposed outside the window for 18 hours, the temperature being kept down by surrounding the flask with ice and water. There was a gain in weight of $0.0069 \mathrm{~g}$, though for at least five hours the sky was cloudy. The ice was then replaced by water kept between $12^{\circ}$ and $18^{\circ}$. The gain in 23 hours in all on four consecutive days was $0.0282 \mathrm{~g}$ more. A slight precipitate formed.

These results make it evident that the action of light has a far greater effect than raising the temperature to $90^{\circ}$.

The observed increase in the weight does not truly represent the amount of oxygen involved, for carbon dioxide, water and volatile organic matter are lost. Twenty-five $g$ of oil $B$ were exposed in a flask having a glass stopper with sealed-in tubes so that a slow current of purified air could be passed over the surface of the oil, carrying the carbon dioxide into baryta water. In seven days, only three of which were sunny, $0.0249 \mathrm{~g}$ of carbon dioxide was found. On exposing the same sample for seven days longer, about four and a half of which were sunny, there was a further formation of $0.0223 \mathrm{~g}$ of carbon dioxide.

In a final experiment, the oil was exposed in an Erlenmeyer flask with glass stopper and delivery tubes. The water formed was carried, by a slow current of dry air passing over the surface of the oil, into a calcium chloride tube and finally weighed. It was noticed that the calcium chloride where the air entered was stained yellow, and that there was a whitish coating on the inside of the tube leading in through the window from the flask. Evidently 
some organic matter was given off. The carbon dioxide was absorbed in baryta water as before, was finally set free by dilute hydrochloric acid, absorbed in a potash bulb, and weighed. The change in weight of the oil was also determined, as well as the amount of the insoluble oxidation product. The following data were obtained after 22 days' constant exposure on the window sill:

Per cent

Gain in weight of oil ................................. 83

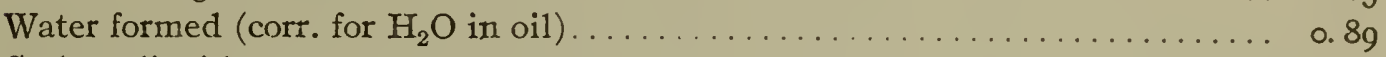

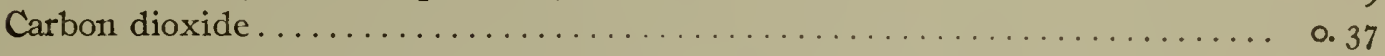

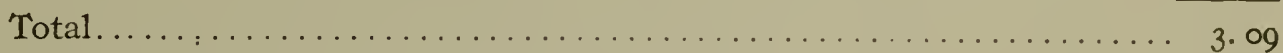

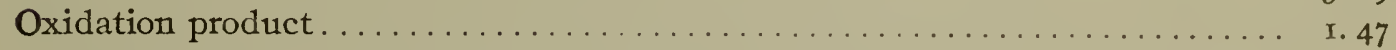

The figures for water and gain in weight of the oil are slightly in error on account of the volatile oily matter mentioned. However, the total of 3.09 per cent agrees closely with the figure 2.89 per cent, obtained by adding the gain in weight of the oil to the oxygen in the carbon dioxide and water found.

The "insoluble" oxidation product dissolves to only a slight extent in ligroin. It is readily filtered on a Gooch crucible, and when washed with ligroin and dried is a light brown powder. It dissolves in strong alcohol and more easily in dilute alcoholic potash. All attempts to crystallize it and to obtain a crystalline potassium salt were fruitless.

The amount found evidently accounts for only a small part of the 1.83 per cent of oxygen taken up by the oil. The following analyses show that a large part of it remains in solution in the oil, or that most of the oil is too slightly oxidized to form the insoluble product.

\begin{tabular}{|c|c|c|c|c|c|c|}
\hline & $\mathrm{C}$ & & II & & 0 & \\
\hline Original oil.. & 86.40 & 86.34 & 13.83 & 13.63 & & \\
\hline Oxidation product. & 72.87 & 72.58 & 7.83 & 7.81 & 19.30 & 19.61 \\
\hline Oil filtered off.. & 84.55 & 84.44 & 13.45 & 13.38 & 2.00 & 2.18 \\
\hline
\end{tabular}

To determine possible changes in the acidity of the oils, 20-g samples of each were exposed, in duplicate, for 23 days. After diluting with benzene, they were titrated with N/IO alkali, using 
phenolphthalein as indicator. The results are calculated as percentages of oleic acid.

\begin{tabular}{|c|c|c|c|c|c|c|}
\hline Sample & B & B & C & C & D & D \\
\hline Original acidity.... & 0.08 & 0.08 & 0.03 & 0.03 & 0.07 & 0.07 \\
\hline Acidity after exposure & 3.66 & 3.75 & 3.29 & 3.30 & 3.00 & \\
\hline
\end{tabular}

Attempts to obtain concordant figures for the permanganate value of the oils were fruitless, as the permanganate was decomposed catalytically, no true end-point being obtained. The oils were shaken with dilute sulphuric acid and heated on the steam bath, standardized permanganate being added from time to time. Apparently the temperature was too high, for it has been shown quite recently by Sarkar and Dutta ${ }^{20}$ that at or above $81^{\circ}$, permanganate is decomposed by manganous sulphate, with formation of manganese peroxide, even in the presence of considerable sulphuric acid. A large amount of peroxide was formed in the attempted oil titrations.

WASHINGTON, September 29, I9IO. 